\title{
COMPÊNDIO DE CIÊNCIA DA RELIGIÃO
}

\author{
Alden Antônio de Araújo*
}

PASSOS, João Décio, e USARSKI, Frank (Orgs.): Compêndio de Ciência da Religião, São Paulo: Paulinas/Paulus, 2013, ISBN 978-85-356-3576-8, 702p.

João Décio Passos e Frank Usarski (Orgs.), na introdução geral do compêndio de Ciência da Religião, apontam a relevância e sentido deste precioso material, elaborado com a finalidade de fornecer uma profunda reflexão e direcionar os rumos das pesquisas que têm por objeto as religiões. Contudo, como destacaremos na sequência desta resenha, há uma lacuna deixada por esta obra ao desconsiderar uma abordagem de gênero do fenômeno religioso.

Segundo esses autores, o compêndio de Ciência da Religião visa apresentar os esforços coletivos para firmar os elementos constitutivos dessa ciência de forma coerente e alinhada. Ele nasce de uma ação conjunta dos(as) cientistas da religião, reconhecendo que o conhecimento acerca de um objeto se dá de modo coletivo, dentro de princípios estabelecidos institucionalmente. Filosoficamente, o compêndio visa exibir de que maneira as diversas áreas do conhecimento interagem entre si na investigação do objeto em comum, no caso a religião. Busca-se uma aproximação que permite uma abordagem transversal do objeto.

O compêndio nos faz refletir sobre o caráter histórico da construção do conhecimento acerca de uma disciplina. Há um acúmulo de estudos que precisam ser considerados e que contribuem enormemente na formação dessa disciplina. Esses estudos permitem um capital disciplinar consolidado e relevante. Mesmo antes do surgimento da

* Mestre em Ciências da Religião pela PUC-SP. Graduado em Filosofia. Atua como professor da Rede Estadual de Ensino. 
disciplina há aproximadamente 150 anos nos currículos oficiais, já havia material suficiente para demonstrar uma busca por legitimação de uma ciência autônoma no estudo da religião. Todos esses estudos acumulados permitiram e já apontavam para uma estruturação da disciplina. Esses estudos foram demarcando os paradigmas básicos para qualquer cientista da religião.

Devido à complexidade do objeto em análise, a ciência da religião deve usar um método que articula as diversas áreas do conhecimento. Isso permite um estudo abrangente e cauteloso que considera a multidimensionalidade da religião. Nesse sentido, a ciência da religião, considerando seu caráter espectral, constrói-se sob o fundamento de duas colunas (histórico/sistemático).

O pilar histórico/empírico aponta os esforços nos estudos empíricos da religião considerando seu caráter diverso e cultural, ou seja, corresponde a uma análise das religiões a partir dos fenômenos particulares em seus contextos limitados no tempo e no espaço. Já o pilar sistemático considera que, de acordo com a variedade de abordagens do fenômeno religioso em suas particularidades empíricas, é possível uma sistematização que leva em conta os aspectos em comum, os traços de semelhança entre as religiões e os conceitos abrangentes dessa realidade complexa, mas passível de compreensão.

Há um consenso entre os(as) cientistas da religião escolhidos(as) para a produção deste compêndio que o/a pesquisador(a) deve se esforçar ao máximo para estabelecer um distanciamento metodológico de seu objeto de estudo. Ou seja, deve buscar certa neutralidade que o/a impeça de fazer julgamentos de valor a respeito da religião estudada. Como afirmam Passos e Usarski, é justamente essa "imparcialidade", essa "neutralidade", que afasta a abordagem do(a) cientista da religião de uma abordagem teológica. Está no cerne da reivindicação da autonomia dessa disciplina essa diferenciação em relação à teologia.

No Brasil, a ciência da religião tem enfrentado diversos desafios que estão enraizados em problemas políticos, culturais e políticos. Historicamente, a ciência da religião divide espaço acadêmico com a teologia. As primeiras investidas dessa ciência em campo nacional são fruto de instituições confessionais, isso tem causado ao longo da história certo 
desafio para se perceber as especificidades epistêmicas que distinguem, obviamente, as duas disciplinas. Internamente a ciência da religião busca definir suas abordagens epistemológicas a fim de esclarecer o modo de relação com seu objeto (religião).

A ciência da religião tem avançado enormemente no Brasil em busca de seu reconhecimento acadêmico. Mesmo não tendo alcançado o estado de ciência normal, em termos kuhnianos, pelo menos do ponto de vista político-institucional, o esforço da comunidade científica tem trazido inúmeros resultados para a consolidação da disciplina no cenário acadêmico. Este compêndio, por exemplo, é fruto desse esforço em busca de reconhecimento e legitimidade. O fato é que, como salienta Passos e Usarski, a ciência da religião se legitima cientificamente, sobretudo, por sua capacidade de articular diversas áreas do conhecimento em torno do fenômeno religioso e a partir de teorias e métodos próprios. Esse caráter trans e interdisciplinar é fundamental para compreender a relevância do estudo da religião proposto nessa disciplina.

$\mathrm{Na}$ introdução geral do compêndio, é possível encontrar o modo como esse material se estrutura considerando os aspectos diacrônicos (histórico/sistemático), metodológicos (métodos reflexivos/métodos empíricos) e funcionais (disciplinas puras/disciplinas aplicadas). Dessa forma, ele é dividido em cinco partes: Epistemologia da Ciência da Religião, que tem o professor Eduardo Cruz como organizador; Ciências Sociais da Religião, organizado pela professora Maria José Rosado-Nunes; a parte Ciências Psicológicas da Religião, organizada pelo professor Edênio Valle; Ciências das linguagens religiosas, que foi organizada pelo professor Ênio José da Costa Brito. Por fim, a quinta parte, Ciência da Religião Aplicada, organizada pelo professor Afonso Maria Ligório Soares.

Este compêndio visa, antes de tudo, oferecer de forma concentrada e devidamente selecionada o conhecimento acumulado até o momento na ciência da religião. Além de instigar novas investidas acadêmicas que venham acrescer no processo de desenvolvimento do conhecimento nessa área.

Para desvelar essa finalidade podemos destacar, como exemplo, a parte designada para discutir o papel e relevância das ciências sociais nos estudos de Religião organizada por Maria José Rosado-Nunes. Por 
meio da leitura desses textos, é possível ter acesso aos principais temas e abordagens que circundam essa área.

Esta parte consta de nove textos escritos por renomados(as) autores(as) na área de Ciências Sociais da Religião. Eles tratam das subdisciplinas que dialogam em torno do objeto de estudo da Ciência da Religião e fornecem um quadro de análise relevante para uma abordagem ampla e reflexiva, que levanta questionamentos e propõe uma profunda discussão em torno do tema religião, contribuindo enormemente no sentido de oferecer subsídio a pesquisadores(as) da área.

O texto de Maria das Dores Campos Machado tem por finalidade apontar a história das Ciências Sociais da Religião, refletindo a abordagem de Durkheim e Weber e a importância que esses dois autores dão à religião, mesmo considerando dinâmicas diferentes. A conclusão da autora implica apontar que o pensamento durkheiminiano considera o fenômeno religioso como elemento constitutivo do fato social, determinando-o e reforçando-o. Já Weber enxerga o processo de racionalização e burocratização como um "caminho sem volta" na vida do homem moderno comprometendo, desse modo, a construção de sentido norteadora da realidade do sujeito.

Outro texto que recorre aos clássicos das Ciências Sociais é apresentado por Marcelo Camurça e reflete sobre as tensões que marcam a constituição de um campo religioso. Espaço relativamente autônomo, sua configuração é devedora de uma estrutura de disputa por capital geradora das tensões. Outro assunto controverso trazido pelo autor é a relação entre os aspectos específicos da religião e a sua inserção na realidade social, que pode promover alterações das estruturas religiosas.

É nesse cenário de tensão e conflito presente nas instituições tradicionais que emergem os novos movimentos religiosos, tema do último texto desta parte do compêndio, escrito por Cecília Loreto Mariz. Esse texto nos remete à realidade contemporânea do fenômeno religioso marcada pela proliferação cada vez mais constante de novos movimentos religiosos que se inserem nesse campo social sempre em tensão com as religiões instituídas. As categorias Weberianas são a lente pela qual a autora fará sua leitura dessa realidade. As religiões tradicionais tendem 
a reagir de maneiras diversas a esses movimentos, seja cooptando-os, incorporando algumas tendências ou, ainda, rejeitando-os.

Ricardo Mariano, autor do texto: Sociologia da Religião e seu foco na secularização, nos mostra como as Ciências Sociais buscaram em sua história se afastar da ideia de uma essência religiosa, fixa e imutável. O caráter dinâmico do fenômeno religioso permite compreender as tensões que o envolvem no decorrer da história. Apesar da leitura pessimista dos fundadores da sociologia acerca do papel da religião no contexto moderno, dada a tese da secularização, o fato é que, a partir de uma constatação empírica, se tem verificado cada vez mais as limitações de tal tese, sobretudo, se considerarmos o papel relevante que o fenômeno religioso tem desenvolvido na contemporaneidade.

A Antropologia da Religião, tema do texto do Professor Silas Guerriero, contribui por considerar a relevância das manifestações religiosas, sejam elas quais forem, para a compreensão do fenômeno religioso. A própria conceituação do que seria "Religião" é um desafio para a abordagem antropológica do fenômeno religioso, sobretudo, porque extrapola os limites impostos pela visão tradicional de religião, propondo um olhar alongado para outras formas de vida religiosa em realidades sociais até então ignoradas na Ciência da Religião.

Destaca-se também o texto de Jens Schlamelcher, que aborda as teorias econômicas no estudo da religião e salienta que religião é também objeto de disputa e conflito de interesses, onde as condições materiais e econômicas nas quais a religião se insere também interferem na dinâmica do fenômeno religioso, implicando um sistema de vantagens e interesses do processo de conversão. Já Sylvio Fausto Gil Filho trata de um assunto recente nos estudos de religião, que é a Geografia da Religião. Sua abordagem remonta à heterogeneidade constitutiva da perspectiva geográfica da religião, fundando-se ora na Geografia Humana, ora na Geografia Cultural, ou ainda em outras abordagens teórico-metodológicas.

O texto de Breno Martins Campos levanta a questão da cientificidade da ciência da religião no que se refere às pesquisas realizadas por cientistas que professam determinada crença religiosa no campo das ciências sociais da religião. Evidentemente, há uma complexidade ine- 
rente dessa relação entre "sujeito/objeto" no estudo da religião, uma vez que, em muitos casos o pesquisador(a) de religião envolvido no campo acadêmico também "joga” o jogo do campo religioso que está pesquisando. Essa realidade implica, por parte do(a) pesquisador(a) religioso(a) que estuda religião, um exercício da ciência comprometido com o espírito crítico e com um método científico válido que se aplique, inclusive, se necessário, na análise científica da própria crença religiosa.

No entanto, cabe ressaltar que este compêndio não cuida com a devida importância outro aspecto que envolve as Ciências Sociais da Religião, que são as questões de gênero. Nesse sentido, pode-se destacar a salutar contribuição da abordagem feminista no estudo das religiões. É evidente que a lacuna deixada neste compêndio de Ciência da Religião, ao não considerar devidamente as relações de gênero no âmbito do fenômeno religioso, acompanha toda a história da disciplina. $\mathrm{Na}$ verdade, essa lacuna marca o estudo de todas as ciências sociais. As relações de gênero, mais uma vez, não são consideradas como aspecto determinante das relações sociais. Quando, na prática, gênero perpassa as estruturas mais profundas de nossa sociedade.

As relações entre os sexos estão entre os fatores determinantes das práticas, discursos e representações religiosas. As religiões se estruturam em torno de um sistema de gênero que molda a organização, a vivência e a relação com o "sagrado". É evidente que os símbolos religiosos, entre outras coisas, formam e definem os papéis de gênero do mesmo modo que estabelece o status das mulheres nas comunidades religiosas e em seu ambiente social.

Os estudos feministas contribuem no sentido de evidenciar como os papéis designados às mulheres não são naturais, mas são construções sociais, sendo assim, esses estudos buscam oferecer uma crítica às teorias que se estruturaram a partir de uma referência patriarcal e que, de maneira sistemática, calou qualquer voz que reivindicasse a igualdade entre os sexos e a emancipação das mulheres, dessa forma, as teorias feministas conduzem para novas categorias analíticas que desvelam aspectos da realidade antes negligenciados por causa da maneira como as questões de gênero foram marginalizadas no cenário social. 
Esta análise teórico-metodológica da realidade proposta pelos estudos feministas pode ser aplicada às Ciências Sociais da religião, uma vez que a maioria das religiões traz em seu âmago um modelo patriarcal. A metodologia feminista apresenta uma nova perspectiva de análise que coloca em evidência a estrutura tendenciosa dos modelos tradicionais dominantes, que distorcem a realidade ao investigar a realidade utilizando categorias próprias do pensamento masculino. Na análise feminista, a experiência das mulheres, realizada pelas mulheres, é o elemento nucleico a partir do qual se questiona a ideia de objetividade e neutralidade propostos pelos paradigmas tradicionais.

$\mathrm{Na}$ academia, as ciências sociais das religiões foram paulatinamente repensadas a partir da intervenção direta ou indireta das estudiosas do feminismo. Na medida em que os estudos de religião foram defrontados com a abordagem teórico-metodológica, proposta pelos estudos feministas, as religiões passaram a ser interrogadas, a partir da perspectiva de gênero, o que permitiu observar por meio de muitas pesquisas empíricas que as práticas, crenças e representações religiosas desempenham função fundamental na legitimação da subordinação das mulheres ou, em outro sentido, apontam para o poder que as religiões possuem como instrumento de superação da opressão e sujeição nas relações sociais entre os sexos. No Brasil, destacam-se por sua importância os seguintes espaços de discussão que oferecem estudos feministas sobre o campo religioso: os Cadernos Pagu, ${ }^{1}$ a Revista Estudos Feministas ${ }^{2}$ e, principalmente, a Revista Mandrágora. ${ }^{3}$ Por meio de trabalhos científicos e publicações, diversas(os) pesquisadoras(es) se esforçam no sentido de aproximar os temas gênero e religião.

Conclui-se, portanto, que a partir da abordagem teórico-metodológica oriunda dos estudos feministas, a Ciência da Religião sofreu uma transformação metodológica e epistemológica, afinal, demonstrou-se como as religiões, para serem compreendidas em suas complexidades

Revista produzida pelo Núcleo de Estudos de Gênero Pagu, da Universidade Estadual de Campinas (UNICAMP).

2 Publicado primeiramente na Universidade Federal do Rio de Janeiro (UFRJ) e, a partir de 1999, passou a ser uma publicação da Universidade Federal de Santa Catarina (UFSC).

3 Revista produzida pela Universidade Metodista de São Paulo (UMESP), que propõe uma discussão do fenômeno religioso tendo em vista o feminismo. 
precisam, entre outros aspectos, considerar a relevância das relações de gênero presentes na manifestação do fenômeno religioso. Esses resultados implicam tanto na análise empírica quanto na própria teoria que tem por finalidade sistematizar os estudos de religião. O compêndio de Ciência da Religião, apesar de sua extrema relevância por ser um primeiro esforço no Brasil de concentrar as possíveis abordagens científicas da religião, ao ignorar as questões de gênero, desvela suas limitações, sobretudo, se considerarmos sua pretensão de ser uma abordagem inter e transdisciplinar do fenômeno religioso. O grande problema deste compêndio é desconsiderar que um/uma pesquisador(a) das religiões, que visa interrogar o campo religioso, não pode deixar de considerar como as relações sociais entre os sexos perpassam e até definem a vivência, a experiência e a prática religiosa. 